\title{
Work hardening behaviour in banded dual phase steel structures with improved formability
}

DOI:

10.1016/j.msea.2017.12.078

\section{Document Version}

Accepted author manuscript

Link to publication record in Manchester Research Explorer

\section{Citation for published version (APA):}

Ennis, B., Bos, C., Aarnts, M. P., Lee, P., \& Jimenez-Melero, E. (2018). Work hardening behaviour in banded dual phase steel structures with improved formability. Materials Science and Engineering A, 713, 278-286.

https://doi.org/10.1016/j.msea.2017.12.078

\section{Published in:}

Materials Science and Engineering A

\section{Citing this paper}

Please note that where the full-text provided on Manchester Research Explorer is the Author Accepted Manuscript or Proof version this may differ from the final Published version. If citing, it is advised that you check and use the publisher's definitive version.

\section{General rights}

Copyright and moral rights for the publications made accessible in the Research Explorer are retained by the authors and/or other copyright owners and it is a condition of accessing publications that users recognise and abide by the legal requirements associated with these rights.

\section{Takedown policy}

If you believe that this document breaches copyright please refer to the University of Manchester's Takedown Procedures [http://man.ac.uk/04Y6Bo] or contact uml.scholarlycommunications@manchester.ac.uk providing relevant details, so we can investigate your claim.

\section{OPEN ACCESS}




\title{
Work hardening behaviour in banded dual phase steel structures
}

\section{with improved formability}

\author{
B.L. Ennis ${ }^{\text {a, }}{ }^{,}{ }^{*}$, C. Bos ${ }^{\text {a }}$, M.P. Aarnts ${ }^{\text {a }}$, P.D. Lee ${ }^{\text {b, }}{ }^{\text {, E. Eimenez-Melero }}{ }^{b}$ \\ ${ }^{a}$ Tata Steel Research and Development, 1970 CA IJmuiden, The Netherlands \\ ${ }^{b}$ The School of Materials, University of Manchester, Oxford Road, Manchester, M13 9PL, UK \\ ${ }^{c}$ Manchester X-Ray Imaging Facility, Research Complex at Harwell, RAL, Didcot, OX11 OFA, UK
}

Corresponding author (*):

B.L. Ennis

Tata Steel Research and Development

1970 CA IJmuiden,

The Netherlands.

E-mail: bernard.ennis@tatasteel.com 


\begin{abstract}
In this work, we show how the presence of microstructural banding and segregation affects the work-hardening behaviour of a dual phase steel with improved formability. This steel contains chemical segregation inherited from the casting process. Our previously developed 3D cellular automaton model allowed us to design thermo-mechanical processes to either promote or suppress banding. The bands are properly described as in-plane sheets of martensite grains. Mechanical testing data revealed a significant reduction in tensile strength in banded structures for a similar level of ductility. The work-hardening behaviour in the pre-yield regime, including the yield strength itself, is not correlated to the incidence of segregation and/or microstructural banding. The reduction in ultimate tensile strength in banded structures stems from a reduced work-hardening capacity in the post-yield regime. This is due to increased austenite stability in the banded steels, coupled to the anisotropic strain localisation in the ferritic matrix between martensite bands.
\end{abstract}

\title{
Keywords
}

Mechanical characterization, hardening, steel, austenite, martensite, thermo-mechanical processing. 


\section{Introduction}

Dual phase steels with improved formability (DH) [1] are of growing importance in the automotive industry, due to demands for steels with ever increasing strength levels without compromising sufficient formability for making complex parts with residual ductility for crash applications. The DH class delivers improved formability over conventional dual phase (DP) steel of the same strength level through the mechanically induced transformation of austenite to martensite (TRIP effect). This requires austenite to be present in its metastable state at room temperature, so that it progressively transforms into martensite upon mechanical deformation. Austenite volume fractions $>10 \mathrm{vol}$ \% can be achieved mainly through the significant carbon enrichment of this phase during material processing. Alloying elements such as silicon and aluminium are added to the steel to delay carbide formation during processing which could otherwise interfere with the carbon enrichment of austenite. Aluminium is becoming increasingly more popular as (partial) replacement for Si in coated steels as it leads to improved coatability [2] and surface finish after hot-rolling and coating $[3,4]$.

In our previous work we demonstrated that micro-segregation patterns of alloying elements present after casting in a high-strength DH steel are retained in the microstructure throughout thermo-mechanical processing, leading to martensite-rich banding in the final microstructure [5]. Aluminium was shown to have a hitherto overlooked role in the segregation of alloying elements during casting, and the single largest influence on the phase transformations occurring during processing that lead to banding in this steel. It is generally accepted that the presence of continuous bands leads to premature failure. In his in situ DIC study of DP steels, Tasan et al. [6] demonstrates that in microstructures where there is a continuous microstructural band, shear bands are forced to develop through the band thereby forcing the banded phase to deform beyond its plastic limit. This is especially true if there is a significant difference in the ultimate strains of the phases composing the banded microstructure. 
Mazinani and Poole showed that the strength of the banded phase also plays an important role [7] and they demonstrated that the nucleation of micro-voids is reduced when the martensite co-deforms with the ferrite matrix. For discontinuous microstructural bands, shear bands naturally cross at the gaps within the band, thereby delaying early damage initiation. Ghadbeigi et al. further observed that the higher the strength of the banded phase, the more strain localisation in the ferrite, causing damage accumulation. The high local strains induced between continuous bands would therefore be more likely to cause damage in the case of high fracture strength martensite [8].

Despite the advances in in situ experimental techniques leading to these discoveries, the influence of banding on the work hardening and fracture behaviour of austenite-containing steels remains less well understood due to the difficulties of resolving this phase using light microscopy, scanning electron microscopy (SEM) and electron backscatter diffraction (EBSD) [9]. Finite element analysis carried out by Shi et al [10] indicated that a random distribution of the austenite phase leads to a higher tensile strength than when located predominantly within the bands. They coupled the strength increase to a lack of localised slip bands in the ferrite matrix in the uniformly dispersed sample. In steels with austenite-enriched bands, confinement of ferrite between connected austenite grains led to increased formation of slip bands within the ferrite matrix, effectively reducing the overall strength of the material. Recently we demonstrated how the mechanically induced austenite transformation contributes to the workhardening in non-banded DH steels. We proposed a physically-based model based on an extended Kocks-Mecking analysis, coupled with in situ high-energy X-ray diffraction data collected upon straining, to describe the effect of the mechanically-induced austenite transformation on the work-hardening behaviour in a non-banded DH steel [11]. In this work, we assessed the effect of banding on the work-hardening behaviour in DH steels, by applying an equivalent physically-based model analysis of the work-hardening behaviour on banded and 
non-banded microstructures of the same DH steel grade. Those microstructures were produced industrially following predictions from a 3D cellular automaton (CA) model [12-14].

\section{Experimental}

\subsection{Material processing}

The steel under investigation is a high-strength dual phase steel with improved formability, termed DH800, produced via continuous casting followed by hot-rolling (HR), cold-rolling (CR) and continuous annealing. The chemical composition of this steel is given in Table 1, together with the segregation coefficient of the relevant elements [5].

Table 1. Chemical composition and average segregation coefficients of the investigated DH800 steel.

\begin{tabular}{lcccccccc}
\hline Element & Fe & $\mathrm{C}$ & $\mathrm{Mn}$ & $\mathrm{Si}$ & $\mathrm{Al}$ & $\mathrm{Cr}$ & $\mathrm{S}$ & $\mathrm{P}$ \\
\hline Composition, wt.\% & Bal. & 0.15 & 2.05 & 0.42 & 0.55 & 0.40 & $<0.01$ & $<0.01$ \\
Segregation coefficient, $(1 / k)$ & - & - & 1.36 & 1.28 & 0.78 & 1.15 & - & - \\
\hline
\end{tabular}

Samples from industrial production material were taken after casting (AC) and further processed in the laboratory for this work. Two slab samples, with dimensions of $135 \times 75 \times$ $225 \mathrm{~mm}^{3}$, were cut from the middle of consecutive slabs produced in an industrial continuous casting line. These samples were further sectioned into three equal sized blocks of $75 \mathrm{~mm}$ in height. The blocks from the middle of the original feedstock were designated S (segregated), since this is the most common section for the appearance of both chemical macro- and microsegregation due to (a) the increased dendrite arm spacing as a result of slower cooling rates and (b) the solute enrichment of the final solidification zone [15]. The blocks taken from the top of the feedstock were designated NS (non-segregated), although the 'S-NS' designation refers to the centre-line (macro) segregation. 
(a)

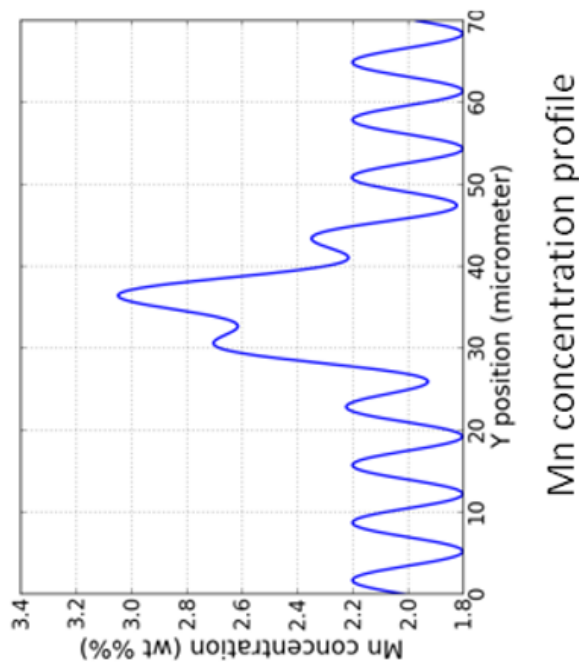

(c)

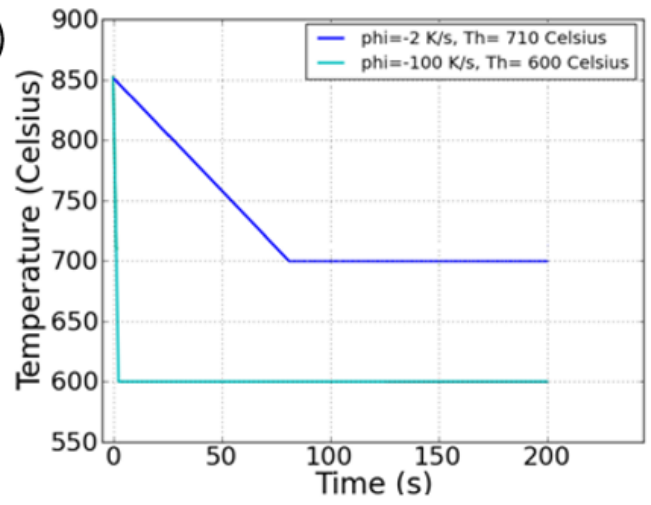

(b)

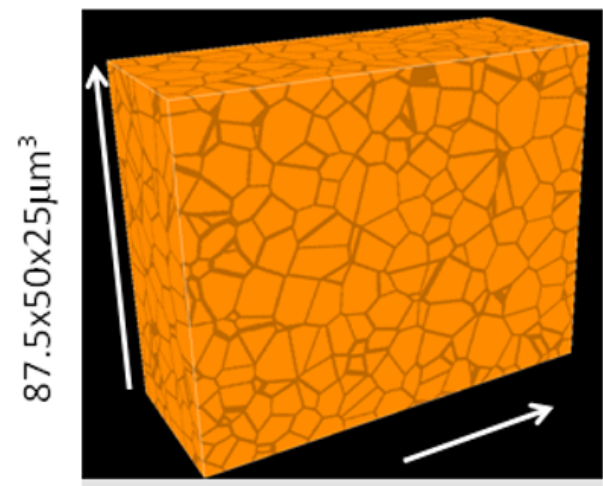

Initial austenite grain size: $7.3 \mu \mathrm{m}$

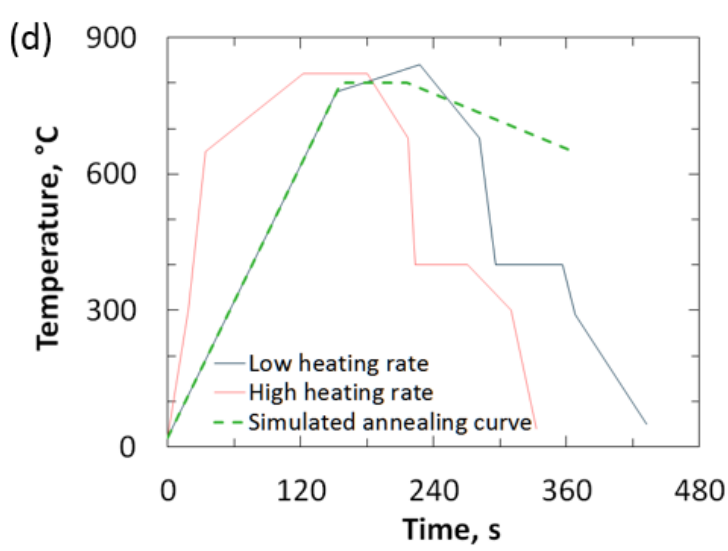

Fig. 1. Settings for CA simulations: (a) Mn concentration profile, (b) Voronoi 3D microstructure elements, (c) cooling trajectories from austenitising to coiling temperatures in the hot-strip mill and (d) thermal cycles used in the annealing simulation after rolling (green dashed line) and in the experiments (solid red and blue lines) $[12,13]$.

The blocks were subsequently hot- and cold-rolled, followed by a continuous annealing designed specifically to either promote or suppress the occurrence of banding in the microstructure, generating B (banded) and NB (non-banded) structures respectively [5]. The annealing process was simulated using a 3D cellular automaton model [12]. The chemical segregation resulting from casting was modelled by combining a sine wave function for the spatial distribution and an analytical function of the effect of chemical concentration on the phase transformation temperature [16]. The resulting function for the concentration profile used 
in the computer simulations is shown in Fig. 1a. This profile is only a function of the $y$ position of a cell, which means that the element concentration is assumed to be constant in the $x$ and $z$ directions. This concentration profile was input into the CA model [12], see Fig. 1b, and the selected cooling trajectories from the temperature of $850^{\circ} \mathrm{C}$ used in the final thickness reduction step during hot rolling are shown in Fig. 1c.

The simulated annealing cycle after hot and cold rolling consisted of heating the deformed microstructure at $5{ }^{\circ} \mathrm{C} / \mathrm{s}$ to $800{ }^{\circ} \mathrm{C}$, holding for $60 \mathrm{~s}$ at this temperature and then cooling down to $650{ }^{\circ} \mathrm{C}$ at $1{ }^{\circ} \mathrm{C} / \mathrm{s}$, as shown in Fig. $1 \mathrm{~d}$. In the industrial annealing cycle, the material is subsequently quenched to room temperature. During quenching martensite formation takes place, which is not accounted for in the model. Since a low heating rate up to the annealing temperature can effectively remove the banding suppression achieved before in the hot-strip mill [17], experimental annealing cycles were adapted to mirror the cooling rate in the hot-rolling process.

One block of each type (NS, S) was used for each of the processing conditions (NB, B), yielding four basic microstructural variants. The main annealing parameters for each variant are given in Table 2, whereas the annealing cycles for both experiment and simulation are shown graphically in Fig. $1 \mathrm{~d}$.

Table 2. Processing conditions and resultant microstructures of each experimental block.

\begin{tabular}{cccccccc}
\hline \multirow{2}{*}{ Designation } & \multirow{2}{*}{ Segregated } & \multicolumn{3}{c}{ Hot-rolling } & \multicolumn{3}{c}{ Annealing } \\
& & FRT, ${ }^{\circ} \mathrm{C}$ & $\varphi,{ }^{\circ} \mathrm{C} / \mathrm{s}$ & $\mathrm{CT},{ }^{\circ} \mathrm{C}$ & $\mathrm{HR},{ }^{\circ} \mathrm{C} / \mathrm{s}$ & $\mathrm{Temp} .,{ }^{\circ} \mathrm{C}$ & Banded \\
\hline NS-NB & No & 900 & 100 & 600 & 19 & 820 & No \\
S-NB & Yes & 900 & 100 & 600 & 19 & 820 & No \\
NS-B & No & 900 & 2 & 700 & 5 & 820 & Yes \\
S-B & Yes & 900 & 2 & 700 & 5 & 820 & Yes \\
\hline
\end{tabular}

The finishing rolling temperature (FRT) was chosen to ensure deformation in the austenite region. The samples were then cooled at different cooling rates $(\varphi)$ through the austenite to ferrite transformation to the intermediate temperature at which the industrial strip 
steel is coiled, namely coiling temperature (CT). After cold-rolling to $1 \mathrm{~mm}$, the samples were heated at different heating rates (HR) to $820^{\circ} \mathrm{C}$, subsequently quenched using helium to the isothermal bainite holding temperature of $425^{\circ} \mathrm{C}$, and held for 60 s prior, and finally quenched to room temperature. The two non-banded steels, namely S-NB and NS-NB, were generated using a high heating rate; the other two (banded) samples S-B and NS-B corresponded to the lower heating rate used in the CA model.

\subsection{Structural characterization}

Samples were taken adjacent to the top and middle blocks of the original as-cast feedstock to determine the degree of chemical segregation after casting. Optical microscopy was carried out on samples from each process variant, in the as hot-rolled (HR), cold-rolled (CR), and cold-rolled \& annealed condition (CRA). In the HR microstructure Nital was used to etch the pearlite phase, which consequently appears dark in the micrographs. In the CRA microstructure $10 \%$ sodium metabisulphite was used to etch the combined martensite $\left(\alpha^{\prime}\right)+$ austenite $(\gamma)$ phase, leaving ferrite lightly etched. The ferrite grain size could thus be measured according to ASTM E112 [18] using Leica QWIN image analysis software with a pixel size of $0.11 \mu \mathrm{m}$. For the banding analysis, the CRA microstructure was etched with LePera reagent, as this provides a better contrast between the ferrite matrix and the combined $\alpha$ ' $\gamma$ second phase. In that case, the matrix is etched (blue) and the second phase is left unetched. Image analysis of the unetched phase therefore results in the combined second phase fraction, $f_{\alpha^{\prime}+\gamma}$. In the CA model structures the matrix phase (ferrite) is coloured blue and the second, carbon-rich, phase is coloured orange. This means that the orange phase in the simulated structures represents pearlite in the HR condition, and martensite + austenite in the CRA condition. The volume fraction of retained austenite $f_{\gamma}$ was measured by X-ray diffraction (XRD) using a fully automated Panalytical Xpert PRO diffractometer. The XRD patterns were recorded in the 20- 
range from 38 to $165^{\circ}$ in reflection mode using Co-K $\mathrm{K}_{\alpha}$ radiation $(\lambda=1.79 \AA)$. The Rietveld analysis of the XRD patterns was carried out using the Bruker TOPAS software package.

The ASTM E1268-99 standard [19] describes the anisotropy index (AI) method to determine the degree of banding in metallic microstructures. This index is determined by the ratio of the average number of interceptions per unit length of test lines perpendicular $\bar{N}_{L \perp}$ and parallel $\bar{N}_{L / /}$ to the deformation direction with the investigated (banded) phase:

$$
A I=\frac{\bar{N}_{L \perp}}{\bar{N}_{L / /}}
$$

Although this metric can distinguish banded and non-banded structures, it cannot adequately discriminate between strongly and weakly banded structures [20]. An alternative approach is based on the measurement of the bi-directional (horizontal and vertical) evolution of the fraction of matrix phase (in this case ferrite) when it is progressively eroded in the two perpendicular directions by a linear increment [9]. The image is converted into a black and white pixel image, and the dark portion is progressive eroded by the linear increment until it has completely decayed to white. In a banded structure, the percentage decay is much more rapid when eroding perpendicular to the rolling direction $(\mathrm{V})$ than parallel to it $(\mathrm{H})$. By defining a characteristic decay distance, $d e^{[H, V]}$, as the one at which the measured fraction of ferrite is equal to $1 /$ e of its initial value, it is then possible to define an "erosion-based" anisotropy index as being the ratio of the decay distances in both directions:

$$
A I=\frac{d e^{H}}{d e^{V}}
$$

The first step in this method is the detection of the phase of interest. This means that for the hot-rolled material the pearlite bands (Nital etching) and for the cold rolled material the martensite-containing bands (10\% sodium metabisulphite etching) are detected as the dark 
phase. No image processing steps were performed on the grey scale input images, these were converted as-is to black and white. The obtained binary image of the detected phase serves as input for the subsequent quantitative image analysis steps. In all cases, a horizontal closure step was applied to the initial binary image to suppress the influence of discontinuous bands. The band continuity could potentially be quantified by varying the number of closures steps [21], but that falls out of the scope of this study.

After phase identification, the area fractions are determined of the binary image after progressive erosion in the vertical $\left(d e^{V}\right)$ and horizontal $\left(d e^{H}\right)$ directions resulting in two area fraction decay curves. This is illustrated in Fig. 2a by the curves with closed (V) and open (H) circles. By subtracting the vertical decay curve from the horizontal decay curve, a difference curve is obtained (solid blue line in Fig. 2a) from which several characteristic values can be extracted. The peak maximum of the difference curve is of itself a measure for the thickness of the bands: the thicker the bands, the larger shift of the maximum to higher erosion values. The position of the peak is also used in defining an objective "erosion-based" anisotropy index, which corresponds to the ratio of horizontal to vertical decay at the peak position. The area under the difference curve (red solid line in Fig. 2a) is a measure for the amount of bands: for strongly banded structures the integrated area curve follows the area detected prior to the erosion steps, however for non-banded structures there will be a big difference between the area detected prior to the erosion steps and the area under the difference curve. To compensate for the grain refinement resulting from cold-rolling, when going from the hot rolled to cold rolled end microstructure, the image of the cold rolled material was taken at 500x whereas the hot rolled product was taken at 200x. Given that this is not exactly equivalent to the actual coldrolling reduction applied $(70 \%)$, the peak maximum is normalised into $\mu \mathrm{m}$ for ease of comparison. 
(a)

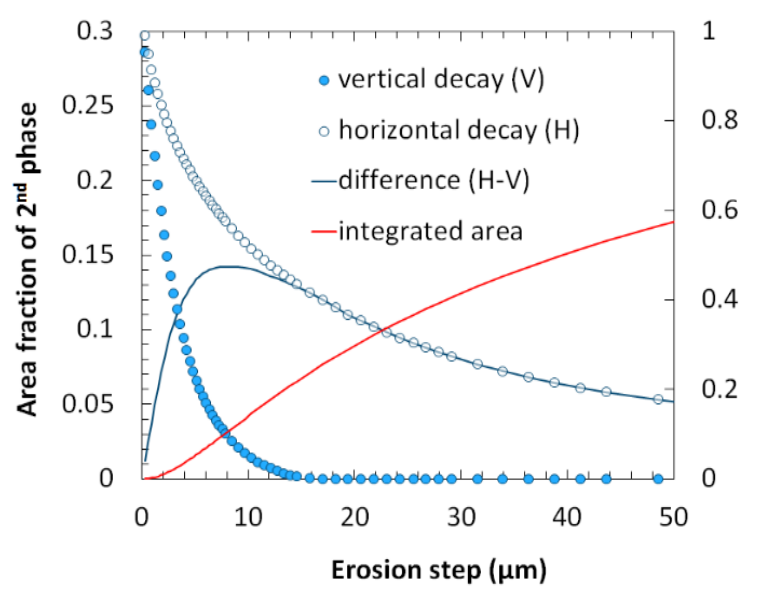

(b) $\quad \square$ Peak<3 $<\mathrm{m} \quad$ Strength

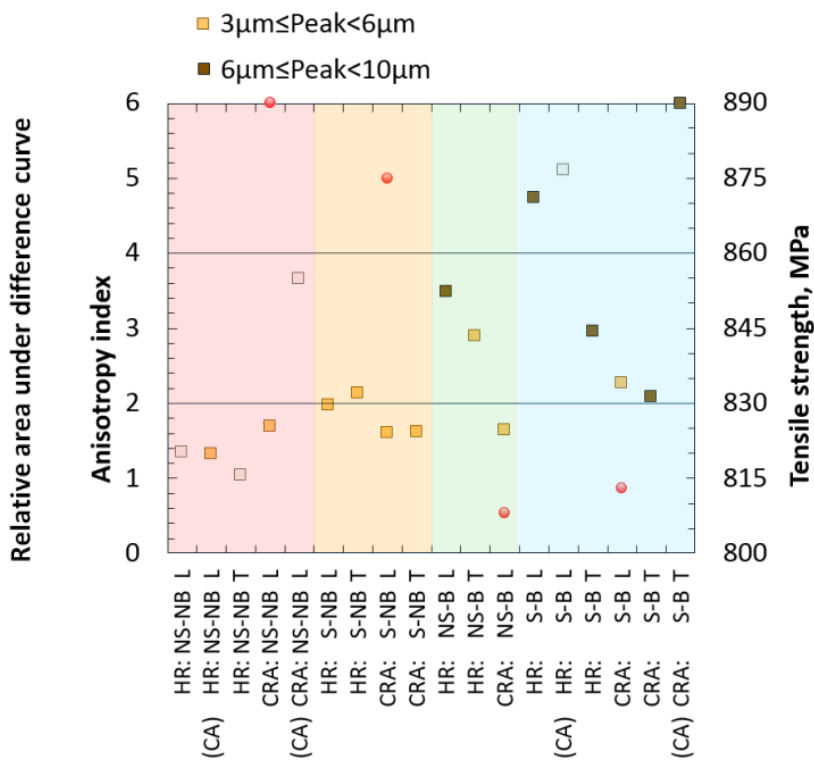

Fig. 2. (a) Illustration of the banding parameters measured by progressive erosion, (b) relationship between anisotropy index and peak maximum position of the different variants after hot-rolling (HR) and after cold-rolling and annealing (CRA). CA indicates microstructures generated by the cellular automaton model simulation; $\mathrm{L}$ and $\mathrm{T}$ indicate the microstructure in the longitudinal and transverse directions respectively. The ultimate tensile strength in the CRA condition is shown by the red circles.

\subsection{Mechanical testing}

Samples were taken from the mid-section of each structural variant and machined into identical tensile specimens with a $50 \mathrm{~mm}$ gauge length per EN ISO 6892-1 [19]. The specimens were strained to failure at room temperature using an Instron $100 \mathrm{kN}$ tensile tester, with the rolling direction parallel to the tensile direction. The strain rate in the gauge length was kept constant at $5 \times 10^{-3} \mathrm{~s}^{-1}$ throughout the test; strain and strain rate were measured and controlled using a clip-on strain gauge.

\section{Results}

\subsection{Microstructure evolution through processing}

In our previous work, we showed the presence of significant banding which was inherited from the cast structure. The counter segregation of $\mathrm{Al}$ on one hand and $\mathrm{Mn}$ and $\mathrm{Si}$ on 
the other tends to promote banding, especially at the centre-line where the macroscopic segregation is the most exaggerated. Segregation factors for the major alloying elements in this steel were calculated as the ratio of the composition of each element at the centre-line to the bulk composition, see Table 1. Banding in this steel appears as continuous strings of martensite grains aligned parallel to the rolling direction. Since the segregation in bands has been shown to be directly inherited from the as cast structure [5], the segregation factors derived are the inverse of the Scheil partitioning coefficient: the values in the table are, thus, in good agreement with other published values of the partitioning coefficient $[23,24]$.

The microstructures in the as-hot rolled condition are shown in Fig. 3, along with the simulated microstructure from the CA model, which shows reasonable agreement with the actual microstructures achieved. This is also reflected in the anisotropy index analysis shown in Fig. 2b, whereby the non-banded microstructures have a low anisotropy and a relatively lower peak position than the banded samples for both the real and simulated microstructures. Whilst it was not possible to suppress banding completely in the segregated sample S-NB, the average grain size and inter-band spacing is significantly reduced when compared to the other segregated sample S-B. The difference between the S-B and NS-B samples is the appearance of more pronounced bands at the centre-line in the S-B sample, as reflected in the higher anisotropy index and peak position in both the longitudinal and transverse directions, see Fig. 2b. The bands in the NS-B sample are more numerous and more closely spaced than in the SB sample. 

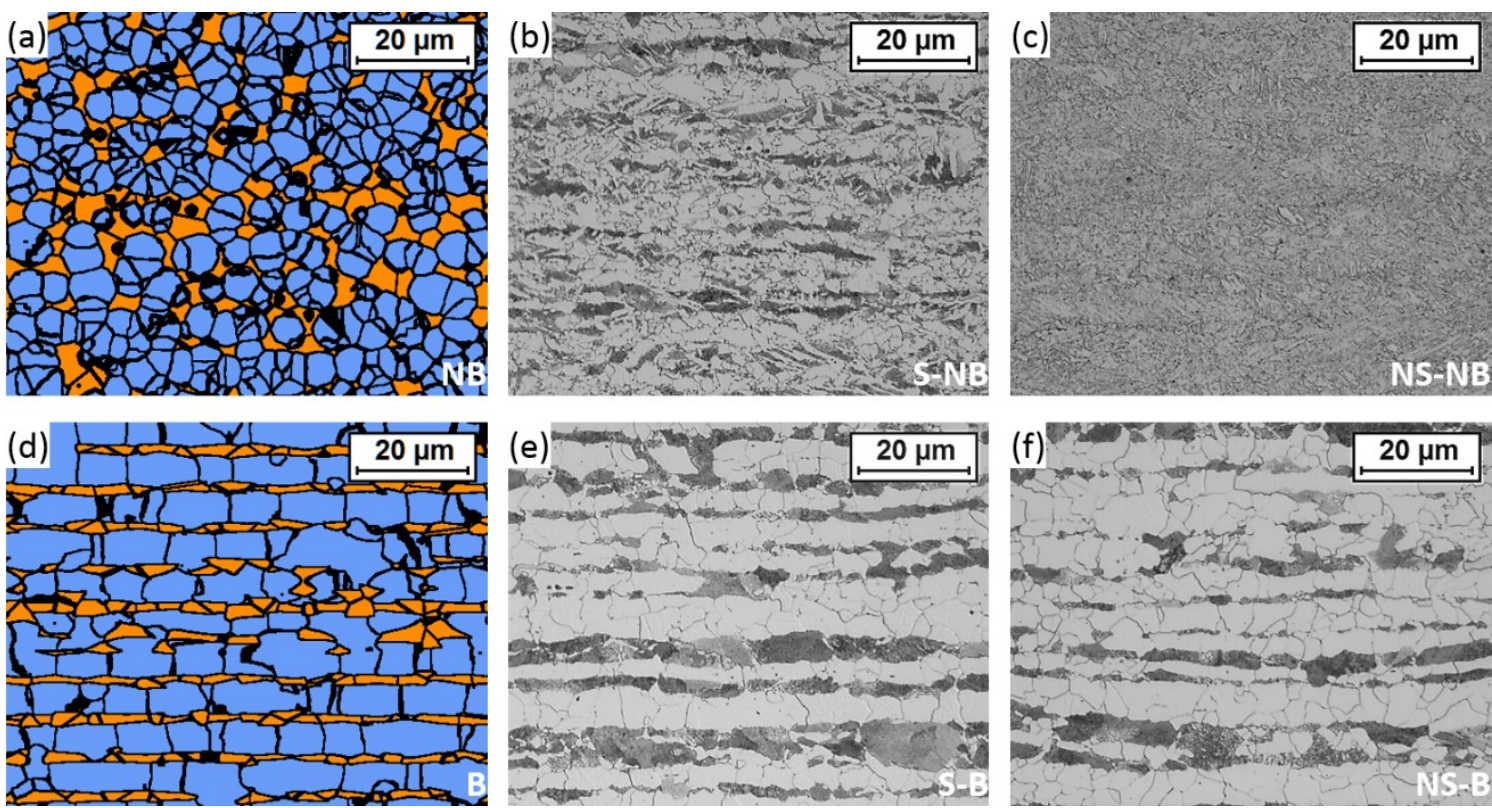

Fig. 3. (a, d) The microstructures predicted by the cellular automaton model in the as hot-rolled (HR) condition for process conditions to suppress (NB) or promote (B) the formation of banding are compared to (b, c, d and e) micrographs of the observed HR structure as etched in $5 \%$ Nital.

The simulated S-SB and S-NB microstructures in the as cold-rolled and annealed (CRA) condition are shown in Figs. 4a and 4d respectively. The CA model simulations show that it is possible to suppress the centre-line band with this process, but that some banding is still present due to micro-segregation. With the notable exception of the NS-NB microstructure, the anisotropy index decreases after cold-rolling and annealing which is not completely captured by the model, see Fig. 2b. Since the CA segregation model is based upon the extrusion into the $\mathrm{z}$ direction of the sine function, the CA model may not be completely valid in describing the 3D grain and alloy distribution. Fig. 4 also contains the real CRA microstructure of the SB and S-NB variants in both the longitudinal and transverse directions. The bands in the S-B sample extend not only parallel to the rolling direction but also perpendicular in the rolling plane, which is consistent with the CA model. These bands extend across the transverse direction of the steel (in plane and perpendicular to the rolling direction) and as such they are 
better described as continuous $2 \mathrm{D}$ bands. Although continuous bands are present in the longitudinal direction of the S-NB sample, they are not present in the transverse direction.
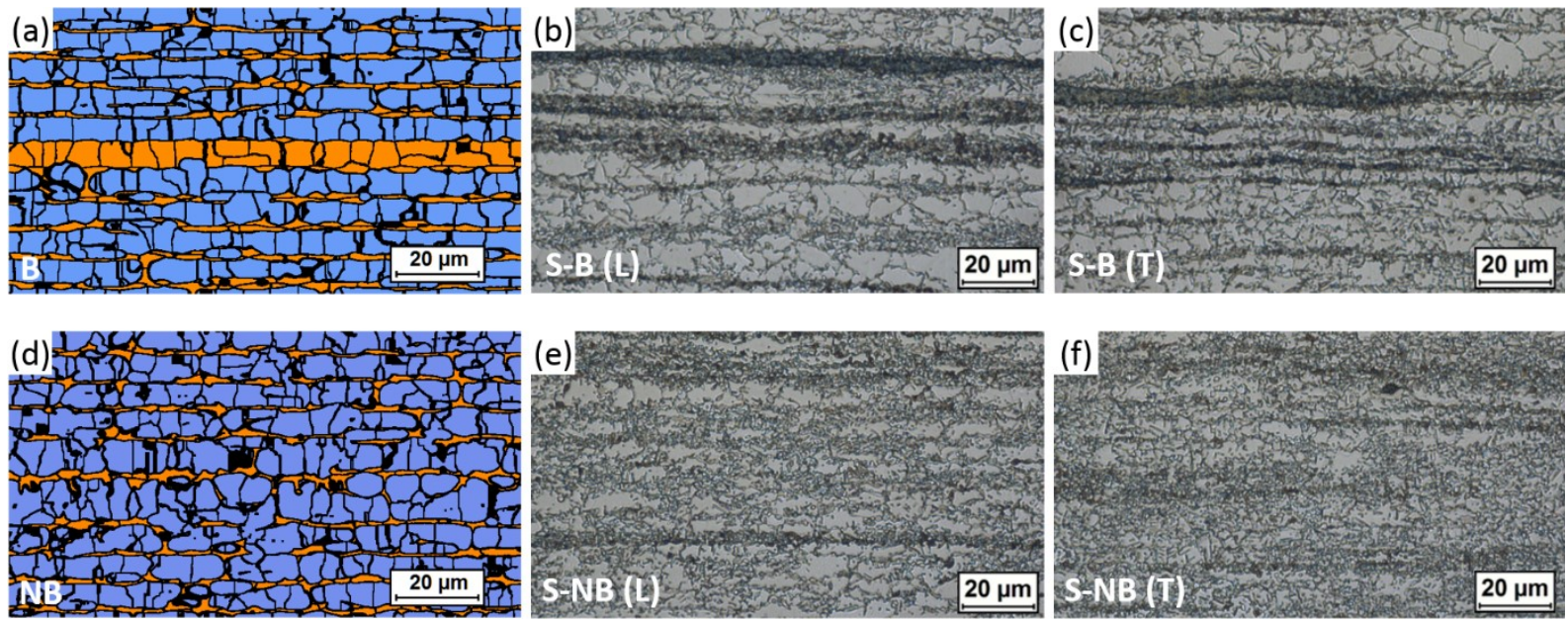

Fig. 4. (a, d) The microstructures predicted by the cellular automaton model in the as coldrolled and annealed condition (CRA) for process conditions to (a) promote (B) or (d) suppress (NB) the formation of banding are compared to the observed microstructures in $(b, e)$ longitudinal and $(c, f)$ transverse directions of $(b, c)$ the segregated and banded variant (S-B) and (e, f) the segregated, non-banded variant (S-NB) as etched with $10 \%$ sodium metabisulphite.

\subsection{Characterization of microstructural variants}

The volume fraction of the combined second phase (including austenite and bainite) in each variant was measured using light optical microscopy (LOM) combined with image analysis, see Table 3. It is not possible to separate austenite and martensite using this technique due to the similarity in colour after etching. For this reason, the retained austenite fraction is determined using XRD, and both its volume fraction and lattice parameter are also given in the table. The martensite fraction is calculated by subtracting the amount of retained austenite, measured by XRD, from the total amount of second phase obtained using light optical microscopy. 
Table 3. Volume fraction and lattice parameter of the second phase constituents in the CRA condition, primarily austenite $(\gamma)$ and martensite $\left(\alpha^{\prime}\right)$, together with the carbon content of both constituents and the ferrite grain diameter $\left(D_{\alpha}\right)$.

\begin{tabular}{ccccccccc}
\hline Variant & $\begin{array}{c}D_{\alpha} \\
(\mu \mathrm{m})\end{array}$ & $\begin{array}{c}f_{\alpha^{\prime}+\gamma} \\
(\mathrm{vol} . \%)\end{array}$ & $\begin{array}{c}f_{\gamma} \\
(\mathrm{vol} . \%)\end{array}$ & $\begin{array}{c}f_{\alpha^{\prime}(\mathrm{LOM})} \\
(\mathrm{vol} \%)\end{array}$ & $f_{\gamma(\text { UTS })} / f_{\gamma^{\prime}}$ & $\begin{array}{c}a_{\gamma} \\
(\AA)\end{array}$ & $\begin{array}{c}{[\mathrm{C}]_{\alpha^{\prime}}} \\
(\mathrm{wt} . \%)\end{array}$ & $\begin{array}{c}{[\mathrm{C}]_{\gamma}} \\
(\text { wt.\%) }\end{array}$ \\
\hline NS-NB & $2.41(38)$ & $22.6(11)$ & $16.2(6)$ & $6.4(13)$ & $0.025(5)$ & $3.602(9)$ & $0.114(3)$ & $0.89(6)$ \\
S-NB & $2.42(27)$ & $19.5(10)$ & $15.6(7)$ & $3.9(12)$ & - & $3.602(4)$ & $0.114(3)$ & $0.94(7)$ \\
NS-B & $2.51(29)$ & $20.1(9)$ & $13.4(7)$ & $6.7(12)$ & - & $3.603(5)$ & $0.114(3)$ & $1.07(7)$ \\
S-B & $2.67(40)$ & $19.9(11)$ & $12.6(7)$ & $7.3(13)$ & $0.20(2)$ & $3.603(6)$ & $0.114(3)$ & $1.13(6)$ \\
\hline
\end{tabular}

The carbon content in austenite $\left(X_{C_{\gamma}}\right)$ was derived by subtracting the amount of carbon in the martensite $\left(X_{C \alpha}\right)$ from the total carbon in the material $\left(X_{C t o t a l}\right)$ :

$$
X_{C_{\gamma}}=X_{C_{\text {total }}}-X_{C_{\alpha \prime}}
$$

Due to the presence of significant quantities of carbide-suppressing elements such as $\mathrm{Al}$ and $\mathrm{Si}$ in this steel $[24,25]$, we can assume that the remaining carbon atoms can be found predominantly in the retained austenite. The carbon content of the martensite was calculated using the following polynomial equation for the martensite start temperature, $M_{s}[26]$ :

$$
M_{S}\left({ }^{\circ} \mathrm{C}\right)=565-\sum_{i} k_{i} x_{i}-600\left(1-e^{-0.96 X_{C_{\alpha \prime}}}\right)
$$

where in this case:

$$
\sum_{i} k_{i} x_{i}\left({ }^{\circ} \mathrm{C}\right)=31 X_{M n}+13 X_{S i}+10 X_{C r}
$$

and for $X_{M n}, X_{S i}$ and $X_{C r}$ we have used the bulk alloy content, since the local alloy content varies from band to band. Given that the materials are subjected to an isothermal bainitic holding treatment at $425^{\circ} \mathrm{C}$ for 60 s prior to quenching to room temperature, austenite grains whose carbon content resulted in an $M_{S}$ at or above the holding temperature will already have transformed to martensite upon quenching from $820^{\circ} \mathrm{C}$ to that isothermal temperature $\left(425^{\circ} \mathrm{C}\right)$. 
Any remaining austenite grains will then be further enriched in carbon through the bainite reaction, thus remaining for the most part in a metastable state at room temperature.

The resulting calculated carbon content in martensite is low enough not to give a significant degree of crystal tetragonality $[27,28]$ and is consistent with the minimum carbon content in austenite of $0.444 \mathrm{wt} . \%$ required for it to remain metastable at room temperature [29]. It is worth noting that the calculated carbon content of the martensite phase in the banded and non-banded variants in the CRA condition does not differ significantly. However, the calculated carbon content of the austenite phase of the banded variants is considerably higher than in the non-banded variants, which will increase the mechanical stability of this phase.

The retained austenite fractions of the NS-NB and S-B variants were also measured at the UTS $\left(f_{\gamma(U T S)}\right)$ and the ratios thereof to the original phase fractions $\left(f_{\gamma 0}\right)$ are also given in the table.

\subsection{Mechanical behaviour}

The equivalent stress-equivalent strain curve for each variant at room temperature is shown in Fig. 5, and the principal mechanical properties are given in Table 4. All variants present a similar mechanical response up to the onset of plastic deformation. The post-yielding properties of the four variants are also relatively close, except for ultimate tensile strength (UTS), which was consistently higher in the non-banded samples than the banded samples.

From Table 3 we can see that the average grain size of the ferrite phase, $D_{\alpha}$, in the CRA condition does not vary significantly across the different microstructural variants, and hence the related Hall-Petch grain boundary strengthening, $\sigma_{y(H P)}$, according to [31]:

$$
\sigma_{y(H P)} \propto \frac{1}{\sqrt{D_{\alpha}}}
$$




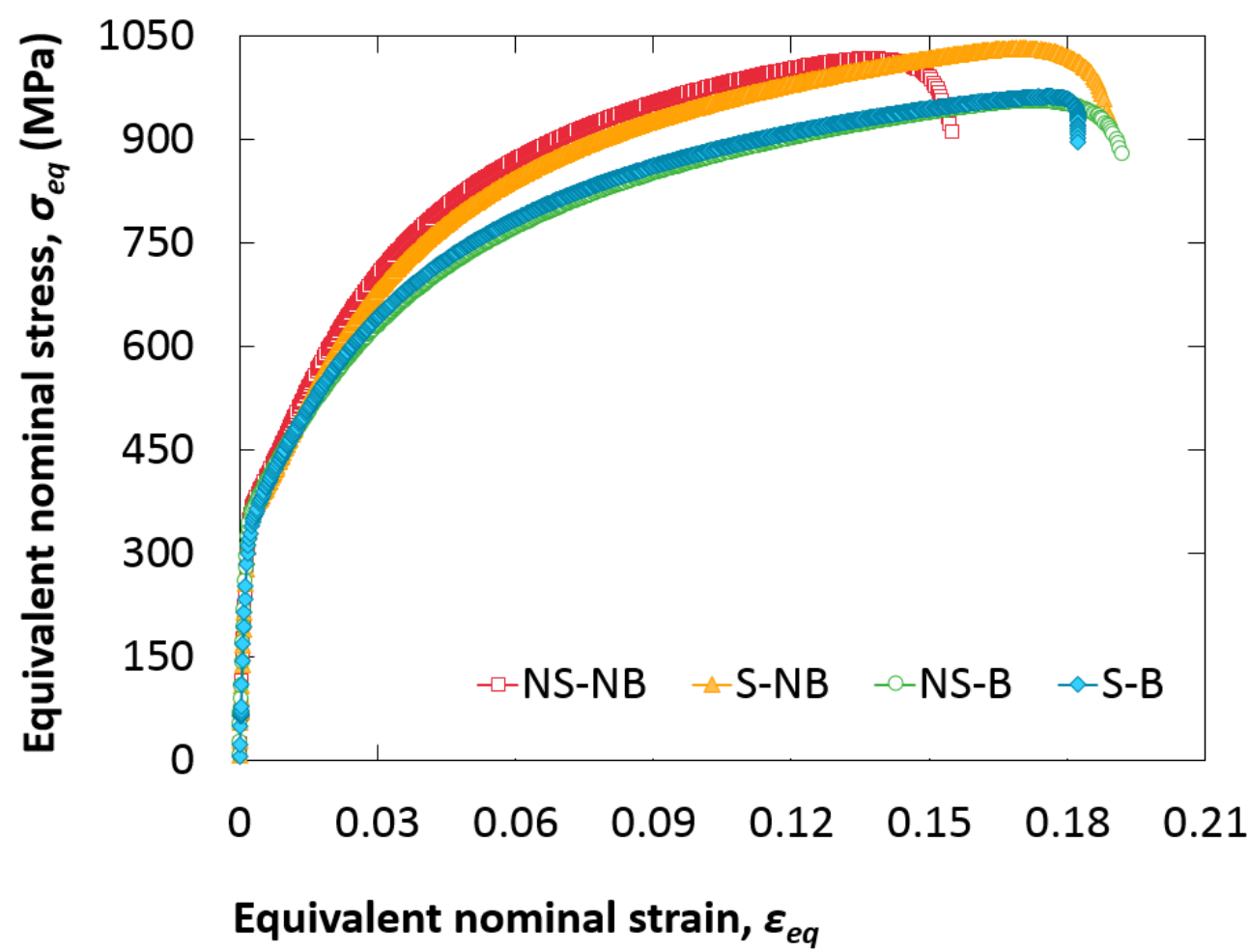

Fig. 5. Equivalent stress of each of the microstructural variants of DH steel as a function of the applied equivalent strain at room temperature.

The sample with highest strength (UTS) and lowest uniform elongation (Au) is the NS-NB sample, which also contains the highest volume fraction and lowest average carbon content of retained austenite. Based on these results, it seems that the volume fraction and overall mechanical stability of the retained austenite are not the only parameters controlling the ductility in banded DH steel structures. 
Table 4. Mechanical properties and initial dislocation structure of different variants in CRA condition. $R p_{0.2}$ is the $0.2 \%$ proof strength, UTS the ultimate tensile strength, Au and At are the uniform and total elongation, respectively. The parameters derived from the extended Kocks-Mecking plot area also given in the table, where $\sigma_{y}$ is the yield stress, $E$ is the elastic modulus, $\Theta_{a}$ the anelastic (pre-yield) work-hardening rate, $L$ is the effective dislocation segment length and $\rho$ is the dislocation density, see Section 4 in the text and ref. [30].

\begin{tabular}{cccccccccc}
\hline & \multicolumn{4}{c}{ Measured tensile properties } & \multicolumn{4}{c}{ Yield stress and dislocation structure } \\
Designation & $R p_{0.2}$ & UTS & Au & At & $\sigma_{y}$ & $E$ & $\Theta_{a}$ & $L$ & $\rho$ \\
& $\mathrm{MPa}$ & $\mathrm{MPa}$ & $\%$ & $\%$ & $\mathrm{MPa}$ & $\mathrm{GPa}$ & $\mathrm{GPa}$ & $\mathrm{nm}$ & $\mathrm{m}^{-2}$ \\
\hline NS-NB & 385 & 890 & 14.1 & 18.9 & 389 & 209 & 5131 & 159 & $3.3 \times 10^{13}$ \\
S-NB & 374 & 875 & 16.1 & 20.4 & 366 & 202 & 4973 & 168 & $3.0 \times 10^{13}$ \\
NS-B & 374 & 808 & 16.5 & 20.8 & 369 & 218 & 4549 & 166 & $3.6 \times 10^{13}$ \\
S-B & 363 & 813 & 15.9 & 19.6 & 353 & 202 & 5161 & 174 & $2.7 \times 10^{13}$ \\
\hline
\end{tabular}

\section{Discussion}

The intercept method for determining the so-called proof stress that characterises yielding, as recommended in international standards [32], can lead in this case to significant errors due to the very high work hardening rate of these DH steels, especially in the early stages of plastic deformation. However, the pre-yield behaviour appears to be similar for each of the microstructural variants. This pre-yield behaviour, which is due to reversible dislocation glide $[30,33]$, is manifested by a drop in the work-hardening rate below the theoretical maximum for a perfectly elastic material, as the applied stress approaches the yield stress. In order to determine accurately the yield stress of these steels, it is necessary to find the transition from the pre-yield, reversible glide regime into irreversible plastic deformation. This pre-yield behaviour is best illustrated using an extended Kocks-Mecking (eK-M) plot of the workhardening rate as a function of the nominal equivalent stress $[11,34]$. 

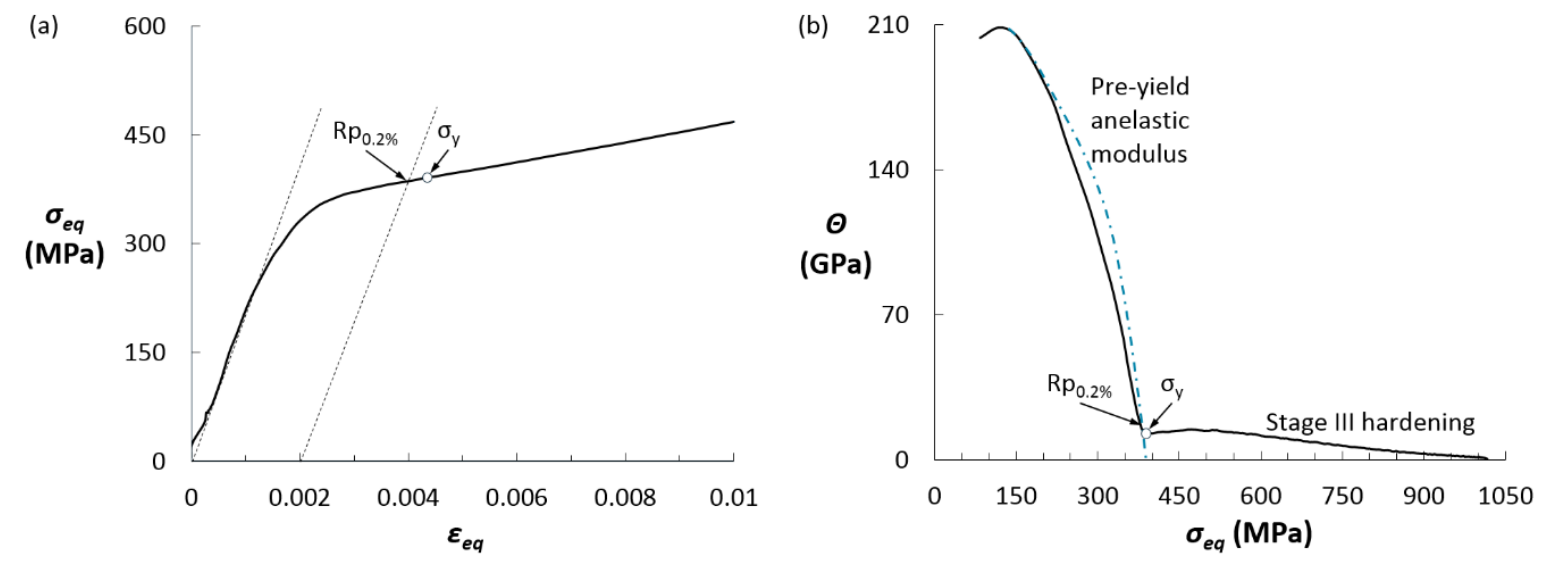

Fig. 6. (a) Yield regime of a tensile test in this case of the NS-NB variant, showing the $R p_{0.2}$ construction and the yield stress determined from (b) extended Kocks-Mecking (KM) plot of the data in (a), showing a well-defined yield point $\left(\sigma_{y}\right)$. The solid line represents experimental data, the blue dashed line the model description of the pre-yield behaviour from Eq. (8), see text.

Fig. 6a shows the low strain portion of the tensile a tensile curve of the NS-NB variant, and the dashed lines illustrate how the $0.2 \%$ proof stress $\left(R p_{0.2}\right)$ is determined. The enlargement of the low-strain data shows that the yield stress, in its physical meaning of the stress at which Frank-Read sources are activated, cannot be determined unambiguously. An alternative representation of the tensile curve is the Kocks-Mecking (KM) plot, which is a graphical representation of the work-hardening rate, $\Theta=\mathrm{d} \sigma_{f} / \mathrm{d} \varepsilon$ vs. the flow stress $\sigma_{f}$, [35-37]. By definition, the flow stress is the sum of the yield stress $\sigma_{y}$ and the work-hardening contribution $\sigma_{w}:$

$$
\sigma_{f}=\sigma_{y}+\sigma_{w}
$$

By extending the curve to include the pre-yield region $\left(\sigma<\sigma_{f}\right)$ and plotting the data against the nominal equivalent stress, see Fig. 6b, we can also derive information regarding the initial dislocation structure. This curve also shows two branches of different slope, with a relatively sharp transition point between them. The approx. linear high-stress part of the KMplot describes the plastic behaviour of the material; the low-stress branch on the other hand, 
provides information on the pre-yield behaviour of the material, and thus on the dislocation structure. This is related to the anelastic work-hardening rate $\left(\Theta_{a}\right)$ as follows $[30,33]$ :

$$
\Theta_{a}=\frac{\bar{M}^{2} E s^{3} \sqrt{1-s^{2}}}{\rho L^{2}(1+v)\left(s-\arcsin (s) \sqrt{1-s^{2}}\right)}
$$

where $\bar{M}$ is the Taylor factor and equals 3.06 [38], $E$ is the elastic modulus whose value is collected in Table 4 for each of the variants, $v$ is the Poisson ratio of ferrite and takes a value of 0.29 [39], $\rho$ is the dislocation density, $L$ is the effective dislocation segment length and $s$ is the ratio of the yield stress to the critical stress, $\sigma_{c}$, for generation of dislocations from a FrankRead source given by:

$$
\sigma_{c}=\frac{\bar{M} G b}{L}
$$

with $G$, the shear modulus $=81 \mathrm{GPa}[40]$ and $b$, the modulus of the Burgers' vector of ferrite $=$ $1 / 2 a<111>=0.248 \mathrm{~nm}$. By combining equations (8) and (9) we can fit the work-hardening behaviour of the different variants from Fig. 7 to derive, and thereby compare the initial dislocation structures. The fit parameters are the effective dislocation segment length, $L$ and dislocation density, $\rho$, which are given in Table 4 for each variant. Since the dislocation segment lengths in a real material form a distribution, this will result in a range of applied stresses at which dislocations will be activated as Frank-Read sources: longer segments at lower stress, shorter segments at higher stress. The extension of the yield-stress range is, thus, directly related to the width of the segment-length distribution: a wider segment-length distribution will cause a more gradual transition between the pre-yield and post-yield ranges in the extended KocksMecking plot. The parameter $L$ should therefore be regarded as an effective segment length related to the effective average yield stress. This approach for deriving the parameters was verified by Arechabaleta et al. by comparing the data from a tensile test to X-ray diffraction measurements [30]. 
As $\sigma$ approaches $\sigma_{\mathrm{c}}$, dislocation segments are activated as Frank-Read sources and the pre-yield behaviour of Eq. (8) changes into the plastic Stage-III behaviour. This transition, clearly present in the extended KM-plot of Fig. 6b, is the physical definition of the yield stress $\sigma_{\mathrm{y}}$. This value can be thus correctly interpreted as the critical stress for generation of dislocations from a Frank-Read source i.e. $\sigma_{c}=\sigma_{y}$. If the pre-yield behaviour consisted solely of linear elastic deformation, then given the generally accepted value of the elastic modulus of the undistorted lattice in steel of $210 \mathrm{GPa}$ [40], the maximum work-hardening rate in the pre-yield regime of a purely elastic material would achieve this value, with a sharp drop at the yield stress. Instead, the initial part of the plot gradually decreases, with a slope that is significantly higher than that of the plastic Stage-III hardening $\left(\Theta_{\text {post }}\right)$ which according to classical dislocation theory follows a linear relationship [41]:

$$
\Theta_{p o s t}=\frac{1}{2}\left(\alpha \bar{M} G b U-\Omega \sigma_{w}\right)
$$

where $U$ and $\Omega$ are the dislocation storage rate and dynamic recovery rate, respectively, $G$ is the elastic shear modulus, $b$ is the Burger's vector, $\sigma_{w}$ is the work-hardening contribution to the flow stress, $M$ is the Taylor factor and $\alpha$ is a material factor related to the dislocation density and distribution.

The extended Kocks-Mecking plot for each microstructural variant is shown in Fig. 7. The data was smoothed using a 5-point quadratic polynomial filter [42]. The data in both Table 4 and Fig. 7 show that there is no clear correlation between microstructural banding and the values for the dislocation density, effective segment length, elastic modulus and yield strength. The observed difference in mechanical behaviour is not significantly affected by the dislocation structure and pre-yield work-hardening behaviour of the original ferritic matrix. The workhardening rate of the different variants lies close to one another at very low stresses. After the maximum value of the work-hardening rate has been reached, it then drops below the theoretical 
maximum for a perfectly elastic material (Young's modulus, E), due to reversible dislocation glide $[30,33]$ as the applied stress approaches the yield stress, which is thus back-calculated from the minimum value of the work-hardening rate.

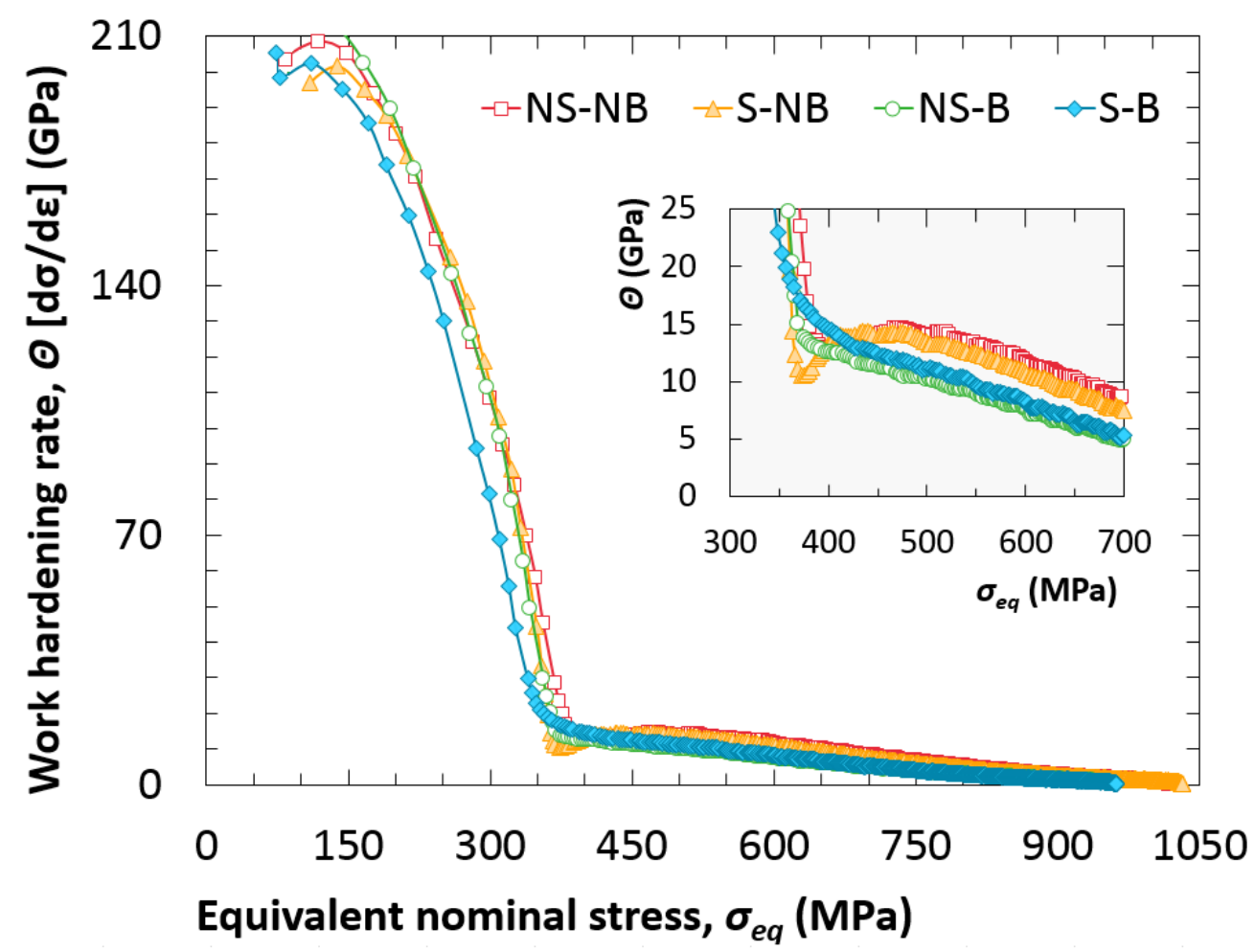

Fig. 7. Work hardening rate of each microstructural variant as a function of the equivalent (true) stress.

The difference in mechanical properties of the different variants can be explained by examination of the work-hardening rate in the post-yield (plastic) regime, see inset of Fig. 7. Firstly, the work-hardening rate of the banded variants do not show clear minima and instead exhibit the gradual transition from pre- to post-yield work-hardening more typical of dual phase steels without retained austenite [11,43-45]. The gradual transition is the result of equalisation of stresses between the martensite and ferrite phases. As demonstrated by Tasan et al. [6] in a banded DP steel, the effect of the martensite bands is to localise the strain into the ferrite phase between the bands. This will induce deformation in the ferrite phase without necessarily activating the mechanical transformation of austenite. By contrast, the non-banded variants 
show the distinctive rise in work-hardening rate at the yield point associated with the austenite transformation [11].

Moreover, the post-yield work-hardening rate is higher for the non-banded steels than for the banded variants, although the slopes of the work-hardening curves of all variants are parallel i.e. a higher contribution of work-hardening stress due to the transformation work. Furthermore, the carbon content of the austenite in the banded variants is significantly higher than in the non-banded variants. This will result in higher mechanical stability of this phase $[46,47]$, and therefore to a lower contribution to the work-hardening rate in the post-yield region. This is supported by the significantly higher fraction of retained austenite remaining at the UTS of the banded variant S-B than in the non-banded variant NS-NB which explains the significantly lower UTS in S-B compared to NS-NB.

\section{Conclusion}

In this work, we have shown how the application of segregation profiles inherited from the casting process in a $3 \mathrm{D}$ cellular automaton model can be reliably used to predict the microstructure of a dual phase steel with improved formability at different stages in the production. Despite the simple 1D description of the chemical segregation in the model, it captures adequately the sheet nature of the martensite grains in the resultant microstructure. Mechanical testing was carried out on samples treated to achieve different combinations of segregation and banding, and the results show a significant reduction in tensile strength in banded steels for a similar level of ductility. The work-hardening behaviour in the pre-yield regime, including the yield strength itself, is not correlated to the incidence of segregation and/or microstructural banding. We demonstrate that the reduction in ultimate tensile strength in banded microstructures is the result of a reduced work-hardening capacity in the post-yield regime. This is due to an increased austenite stability in the banded steels, coupled to the anisotropic strain localisation in the ferrite matrix between the martensite bands. 


\section{Acknowledgements}

This work was made possible by the facilities and support of Tata Steel, the DiamondManchester Collaboration and the Research Complex at Harwell, funded in part by EPSRC $(\mathrm{EP} / \mathrm{I} 02249 \mathrm{X} / 1)$.

\section{Data Statement}

A representative sample of research data from the experiments along with the plot data for the graphs in this manuscript is provided in supplementary material: [doi: $10.17632 / 4 \mathrm{pdrfnn} 3 \mathrm{kn} .1$ ].

\section{References}

[1] German Association of the Automotive Industry (VDA), VDA 239-100 Sheet Steel for Cold Forming, (2016). https://www.vda.de/en/services/Publications/vda-239-100.html.

[2] M. De Meyer, D. Vanderschueren, B.C. De Cooman, The influence of the substitution of Si by Al on the properties of cold-rolled C-Mn-Si TRIP steels, ISIJ Int. 39 (1999) 813-822. doi:10.2355/isijinternational.39.813.

[3] K. Eberle, P. Cantinieaux, P. Harlet, New thermomechanical strategies for the production of high strength low alloyed multiphase steel showing a transformation induced plasticity (TRIP) effect, Steel Res. 70 (1999) 233-238.

[4] J. Maki, J. Mahieu, B.C. De Cooman, S. Claessens, Hot-dip galvanising of Si-free CMn-Al TRIP steels, in: M. Lamberights, C. de R.M. (CRM) (Eds.), Galvatech 2001, Verlag Stahleisen, 2001: pp. 623-630.

[5] B.L. Ennis, E. Jimenez-Melero, R. Mostert, M.B. Santillana, P.D. Lee, The role of aluminium in chemical and phase segregation in a TRIP-assisted dual phase steel, Acta Mater. 115 (2016) 132-142. doi:10.1016/j.actamat.2016.05.046.

[6] C.C. Tasan, J.P.M. Hoefnagels, M.G.D. Geers, Microstructural banding effects clarified through micrographic digital image correlation, Scr. Mater. 62 (2010) 835838. doi:10.1016/j.scriptamat.2010.02.014.

[7] M. Mazinani, W.J. Poole, Effect of Martensite Plasticity on the Deformation Behavior of a Low-Carbon Dual-Phase Steel, Metall. Mater. Trans. A. 38 (2007) 328-339. doi:10.1007/s11661-006-9023-3.

[8] H. Ghadbeigi, C. Pinna, S. Celotto, J.R. Yates, Local plastic strain evolution in a high 
strength dual-phase steel, Mater. Sci. Eng. A. 527 (2010) 5026-5032.

doi:10.1016/j.msea.2010.04.052.

[9] M.P. Aarnts, M. Zuiderwijk, R.A. Rijkenberg, A. Arlazarov, D. Barbier, A. Hazotte, B. Krebs, L. Germain, M. Gouné, L. Barbé, J. Kommenda, O. Karlsson, J. Hagström, M. Fischer, F. Friedel, V. Marx, E. Füreder, C. Commenda, Microstructural quantification of multi-phase steels (Micro-quant), European Commission, Brussels, Belgium, 2011. doi: $10.2777 / 83656$.

[10] J. Shi, S. Turteltaub, E. Van der Giessen, Analysis of banded morphology in multiphase steels based on a discrete dislocation-transformation model, Model. Simul. Mater. Sci. Eng. 19 (2011) 74006. doi:10.1088/0965-0393/19/7/074006.

[11] B.L. Ennis, E. Jimenez-Melero, E.H. Atzema, M. Krugla, M.A. Azeem, D. Rowley, D. Daisenberger, D.N. Hanlon, P.D. Lee, Metastable austenite driven work-hardening behaviour in a TRIP-assisted dual phase steel, Int. J. Plast. 88 (2017) 126-139. doi:10.1016/j.ijplas.2016.10.005.

[12] C. Bos, M.G. Mecozzi, D.N. Hanlon, M.P. Aarnts, J. Sietsma, Application of a ThreeDimensional Microstructure Evolution Model to Identify Key Process Settings for the Production of Dual-Phase Steels, Metall. Mater. Trans. A. 42 (2011) 3602-3610. doi:10.1007/s11661-011-0696-x.

[13] C. Bos, M.G. Mecozzi, J. Sietsma, A microstructure model for recrystallisation and phase transformation during the dual-phase steel annealing cycle, Comput. Mater. Sci. 48 (2010) 692-699. doi:10.1016/j.commatsci.2010.03.010.

[14] M.G. Mecozzi, C. Bos, J. Sietsma, Microstructure Modelling of Solid-State Transformations in Low-Alloy Steel Production , Mater. Sci. Forum. 706-709 (2012) 2782-2787. doi:10.4028/www.scientific.net/MSF.706-709.2782.

[15] S. Karagadde, L. Yuan, N. Shevchenko, S. Eckert, P.D. Lee, 3-D microstructural model of freckle formation validated using in situ experiments, Acta Mater. 79 (2014) 168-180. doi:10.1016/j.actamat.2014.07.002.

[16] B.L. Ennis, E. Jimenez-Melero, R. Mostert, B. Santillana, P.D. Lee, Dataset concerning the analytical approximation of the Ae3 temperature, Data Br. 10 (2017) 330-334. doi:10.1016/j.dib.2016.11.073. 
[17] F.G. Caballero, A. García-Junceda, C. Capdevila, C. García de Andrés, Evolution of Microstructural Banding during the Manufacturing Process of Dual Phase Steels, Mater. Trans. 47 (2006) 2269-2276. doi:10.2320/matertrans.47.2269.

[18] ASTM, E112-10 Standard Test Methods for Determining Average Grain Size, in: Annu. B. ASTM Stand. Vol. 03.01, Met. -mechanical Testing; Elev. Low-Temperature Tests Metallogr., ASTM International, West Conshohocken, PA, USA, 2011.

[19] ASTM, E1268-99 Standard practice for assessing the degree of banding or orientation of microstructures (reapproved 2001, 2007), in: Annu. B. ASTM Stand. Vol. 03.01, Met. -mechanical Testing; Elev. Low-Temperature Tests Metallogr., ASTM International, West Conshohocken, PA, USA, 2000: pp. 820-848.

[20] B. Krebs, A. Hazotte, L. Germain, M. Gouné, Quantitative analysis of banded structures in dual-phase steels, Image Anal. Stereol. 29 (2010) 85-90. doi:10.5566/ias.v29.p85-90.

[21] K.S. McGarrity, J. Sietsma, G. Jongbloed, Characterisation and quantification of microstructural banding in dual phase steels Part 1 - General 2D study, Mater. Sci. Technol. 28 (2012) 895-902. doi:10.1179/1743284712Y.0000000004.

[22] R.M. Fisher, G.R. Speich, L.J. Cuddy, H. Hu, Phase transformations during steel production, in: Proc. Darken Conf. "Physical Chem. Metall., US Steel, Monroeville, PA, USA, 1976: pp. 463-488.

[23] D. Chakrabarti, C. Davis, M. Strangwood, Characterisation of bimodal grain structures in HSLA steels, Mater. Charact. 58 (2007) 423-438. doi:10.1016/j.matchar.2006.06.014.

[24] M. Gomez, C.I. Garcia, D.M. Haezebrouck, A.J. Deardo, Design of Composition in (Al/Si)-alloyed TRIP Steels, ISIJ Int. 49 (2009) 302-311. doi:10.2355/isijinternational.49.302.

[25] D. Simonovic, C.K. Ande, A.I. Duff, F. Syahputra, M.H.F. Sluiter, Diffusion of carbon in bcc Fe in the presence of Si, Phys. Rev. B. 81 (2010) 54116. doi:10.1103/PhysRevB.81.054116.

[26] S.M.C. van Bohemen, Bainite and martensite start temperature calculated with exponential carbon dependence, Mater. Sci. Technol. 28 (2012) 487-495. 
doi:10.1179/1743284711Y.0000000097.

[27] G. Kurdjumow, E. Kaminsky, Eine röntgenographische Untersuchung der Struktur des gehärteten Kohlenstoffstahls, Zeitschrift Für Phys. 53 (1929) 696-707. doi:10.1007/BF01330828.

[28] J. Mazur, Lattice parameters of martensite and austenite, Nature. 166 (1950) 828.

[29] W.J. Wrazej, Lattice spacing of retained austenite in iron-carbon alloys, Nature. 163 (1949) 212-213.

[30] Z. Arechabaleta, P. van Liempt, J. Sietsma, Quantification of dislocation structures from anelastic deformation behaviour, Acta Mater. 115 (2016) 314-323. doi:10.1016/j.actamat.2016.05.040.

[31] F.B. Pickering, Structure-property relationships in steels, in: Cahn et al (Ed.), Wiley, 1993: pp. 45-79.

[32] The International Organisation for Standardisation (ISO), ISO 6892-1: "Metallic materials - tensile testing - part 1: method of testing at ambient temperature," Geneve, Switzerland, 2016.

[33] P. van Liempt, J. Sietsma, A physically based yield criterion I. Determination of the yield stress based on analysis of pre-yield dislocation behaviour, Mater. Sci. Eng. A. 662 (2016) 80-87. doi:10.1016/j.msea.2016.03.013.

[34] H. Mecking, U.F. Kocks, Kinetics of flow and strain-hardening, Acta Metall. 29 (1981) 1865-1875. doi:10.1016/0001-6160(81)90112-7.

[35] U.F. Kocks, Laws for Work-Hardening and Low-Temperature Creep, J. Eng. Mater. Technol. 98 (1976) 76. doi:10.1115/1.3443340.

[36] H. Mecking, Work hardening of single-phase polycrystals , in: Encycl. Mater. Sci. Technol., Elsevier Science, London,UK, 2001: pp. 9785-9795.

[37] U.F. Kocks, H. Mecking, Physics and phenomenology of strain hardening: the FCC case, Prog. Mater. Sci. 48 (2003) 171-273. doi:10.1016/S0079-6425(02)00003-8.

[38] R.E. Stoller, S.J. Zinkle, On the relationship between uniaxial yield strength and resolved shear stress in polycrystalline materials, J. Nucl. Mater. 283-287 (2000) 349352. doi:10.1016/S0022-3115(00)00378-0. 
[39] J.A. Benito, J. Jorba, J.M. Manero, A. Roca, Change of Young's modulus of colddeformed pure iron in a tensile test, Metall. Mater. Trans. A. 36 (2005) 3317-3324. doi:10.1007/s11661-005-0006-6.

[40] G. Ghosh, G.B. Olson, The isotropic shear modulus of multicomponent Fe-base solid solutions, Acta Mater. 50 (2002) 2655-2675. doi:10.1016/S1359-6454(02)00096-4.

[41] H. Mecking, U.F. Kocks, Kinetics of flow and strain-hardening, Acta Metall. 29 (1981) 1865-1875. doi:10.1016/0001-6160(81)90112-7.

[42] A. Savitzky, M.J.E. Golay, Smoothing and Differentiation of Data by Simplified Least Squares Procedures., Anal. Chem. 36 (1964) 1627-1639. doi:10.1021/ac60214a047.

[43] P. van Liempt, Workhardening and substructural geometry of metals, J. Mater. Process. Technol. 45 (1994) 459-464. doi:10.1016/0924-0136(94)90382-4.

[44] H. Vegter, P. van Liempt, Proceedings of the 13th International Conference on Metal Forming, Steel Res. Int. 81 (2010) n/a-n/a. doi:10.1002/srin.201190002.

[45] Y. Bergström, A dislocation model for the stress-strain behaviour of polycrystalline $\alpha$ Fe with special emphasis on the variation of the densities of mobile and immobile dislocations, Mater. Sci. Eng. 5 (1970) 193-200. doi:10.1016/0025-5416(70)90081-9.

[46] E. Jimenez-Melero, N.H. van Dijk, L. Zhao, J. Sietsma, S.E. Offerman, J.P. Wright, S. van der Zwaag, Martensitic transformation of individual grains in low-alloyed TRIP steels, Scr. Mater. 56 (2007) 421-424. doi:10.1016/j.scriptamat.2006.10.041.

[47] R. Blondé, E. Jimenez-Melero, L. Zhao, J.P. Wright, E. Brück, S. van der Zwaag, N.H. van Dijk, High-energy X-ray diffraction study on the temperature-dependent mechanical stability of retained austenite in low-alloyed TRIP steels, Acta Mater. 60 (2012) 565-577. doi:10.1016/j.actamat.2011.10.019. 